\title{
Application of Causal Inference Analysis Economic Growth on Labor Production from Foreign Direct Investment
}

\author{
Po Sheng Ko, ${ }^{1}$ Kuo Chih Lu, ${ }^{2}$ Cheng Chung Wu $\mathbb{D},{ }^{3}$ and Tiantong Yuan ${ }^{4}$ \\ ${ }^{1}$ Department of Public Finance and Taxation, National Kaohsiung University of Science and Technology, Kaohsiung, Taiwan \\ ${ }^{2}$ Department of International Business, National Kaohsiung University of Science and Technology, Kaohsiung, Taiwan \\ ${ }^{3}$ Department of Finance, Suqian College, Suqian, Jiangsu, China \\ ${ }^{4}$ Department of Business Administration, Krirk University, Bangkok, Thailand
}

Correspondence should be addressed to Cheng Chung Wu; wu_0110@yahoo.com.tw

Received 5 September 2019; Revised 7 February 2020; Accepted 15 February 2020; Published 16 March 2020

Guest Editor: Murari Andrea

Copyright ( $\odot 2020$ Po Sheng Ko et al. This is an open access article distributed under the Creative Commons Attribution License, which permits unrestricted use, distribution, and reproduction in any medium, provided the original work is properly cited.

\begin{abstract}
In recent four decades, policy reform has integrated China's economy into global. Since 1981, foreign direct investment (FDI) has been gradually flowing into the Yangtze River Delta region. As a result, this region has enjoyed strong economic strength based on abundant human resources and convenient transportation network. Shanghai, the key city, has become one of the major cites attracting FDI; meanwhile, FDI also has had a tremendous impact on Shanghai's economic development, including employment. To sum up, Shanghai has been chosen as the research object in this paper. This research is organized by four parts: firstly, a theoretical analysis of employment effects of FDI is presented; secondly, after combining the actual utilization of FDI and employment in Shanghai, an empirical analysis of the effects of FDI on employment quantity and employment quality is carried out by data and regression models; thirdly, this research found FDI has exerted a negative influence on employment quantity in Shanghai; moreover, FDI also has shown a positive impact on the employment quality; and finally, the paper has proposed some suggestions to FDI's utility in the future.
\end{abstract}

\section{Introduction}

In the last decade, China has grown rapidly because of FDI and replaced the United States as the world's largest recipient of FDI in 2002. Shanghai is the metropolitan area of the Yangtze River Delta and has exceptional conditions to attract foreign investment. Therefore, Shanghai has turned into a major recipient of FDI in China. The massive FDI inflows had many significant effects on Shanghai with many aspects, and the change of local employment is one of the major effects. This research selects Shanghai as the research subject and focuses on studying the effects of FDI on the change of local employment, such as employment quantity, employment distribution, and employment quality as three sectors of the economy.

The primary sector involves the retrieval and production of raw materials, such as corn, coal, wood, and iron. The secondary sector involves the transformation of raw or intermediate materials into goods, such as manufacturing steel into cars or textiles into clothing. The tertiary sector involves supplying of services to consumers and businesses, such as baby-sitting, cinema, and banking. In fact, all three sectors are affected by FDI; however, some sectors are affected significantly while others are not.

The effects of FDI on the employment distribution in the three sectors will vary because of different scope of influence from FDI in each sector. Compared with other sectors, the impact from FDI on the primary sector is not significant. The secondary sector always plays the leading role in China national economy, and FDI weighs heavily in this sector. Therefore, FDI has a more significant influence on employment in this sector. Foreign companies increase their direct investment into the tertiary sector, which causes the labor demand increase in the service industry. Therefore, FDI surely has a greater scope of influence on employment quantity in the tertiary sector. 
FDI has two effects that are direct generation effect and indirect generation effect. Direct generation effect creates job opportunities in the home country through subsidiaries or operation bases, while indirect generation effect means the job opportunities increase in host countries through other approaches and spillover effect.

Most of the time, FDI has a direct positive effect on the number employed in the foreign companies and indirect positive or negative effect on total employment quantity in Shanghai since the total employment demand is an inverted $U$ curve along with the FDI amount [1]. For example, in recent years, both the number of employees in foreign companies and total employment had an obvious rising trend; however, researchers still cannot assert the FDI has a full positive effect for total employment since some other reasons may also cause the total employment to rise, FDI just one of many reasons.

Furthermore, FDI normally requires a high-quality job that offers high salary with high requirement and high work efficiency; however, if the work amount does not change, high work efficiency will signify lesser labor demand. Crowding-out effect would also appear when an international company enters the market through "merger" or "acquisition," a reasonable downsizing of employee amount occurs cutting down employment as the result.

In addition, FDI has both positive and negative effects on employment quality. Foreign companies often offer better wages, benefit packages, and working environment, as well as quality training. Meanwhile, more foreign enterprises discriminate against the host country's social security system for their employees.

According to Ko et al. [2], a theoretical analysis applied on how FDI affects the employment is presented. Secondly, an empirical analysis of FDI effects on employment's quantity, employment's distribution, and employment's quality is carried out by collecting relevant data and establishing regression models, with combining the actual utilization of FDI and employment in Shanghai. This study finds that although FDI does exert a positive influence on the quantity of employment in Shanghai's tertiary industry, FDI is not conducive to primary and secondary industries. In addition, FDI has shown positive and negative impacts on the quality of employment [1]. Besides, the paper will propose some suggestions in order to enhance the positive effects of FDI on employment. Finally, the researchers will propose two regression models to test the actual effect of FDI on employment, which are as follows: Model A is used to test the FDI's effect on total employment, and then, Model B has added $W / P$ variable to test the FDI's effect for employment quality. Moreover, employment distribution in three sectors is analyzed by second-hand statistic data.

\section{Review of the Literature}

FDI refers to "Foreign Direct Investment," also known as "Direct International Investment," which means investors participate in the entity's production and operation and exercise substantial control over management. The yield relies on the condition of the entity's operation and exhibits high variability. Most of the scholars suggest that the employment effects caused by FDI in the host countries are mainly on three aspects: employment quantity, employment distribution, and employment quality. The authors are interested in finding the impacts of FDI inflow on employment quantity, employment distribution, and employment quality by analysis effects of FDI in three economic sectors.

2.1. Effects on Employment Quantity. Tang [3] believes that FDI causes both positive and negative effects on the employment quantity. For example, FDI will increase job opportunities, which is a positive employment-generation effect; meanwhile, the international enterprises' entering will cause crowding-out effect, a negative employment-generation effect that results in reducing existing employees.

FDI will create considerable job opportunities and boost employment. Generally, direct generation effect means the FDI creates job opportunities and increases employment directly in the host country. When an international company enters with "Greenfield Investment," it will bring net capital into the host country, the international company will establish subsidiaries or an operation base there, and then newly-founded companies will recruit local people and increase employment in the host country.

Indirect generation effect means the job opportunities in host countries are increased with other approaches such as expatriate and work permit. Generally, the FDI will form an "enterprise-correlation effect" by increasing the job opportunities in local companies which associate with the intercountry companies. Entering of the FDI's companies will drive the operation of the local companies. When the demand of the foreign companies is equal to the output of domestic companies, the demand of the products will rise, and then the local companies' scale of production will be expanded. The labor demand of domestic companies will have a surplus due to the shortage of employees, and then the domestic companies will have to recruit new employees in order to increase productivity; therefore, new job opportunities will be generated indirectly.

Moreover, FDI increases the employment quantity indirectly by the "spillover effect." Foreign companies introduce new technologies and new types of industry into the host countries. Meanwhile, it will accelerate the development of the latest high-tech industry in the host countries and increase employment in multifarious industries. Therefore, numerous job opportunities will be generated indirectly. In addition, the FDI inflow brings capital which will rapidly spur productivity like the effect of economy of scale. As a result, the host countries' factors of production will be properly dispensed, and the not-utilized factors will be able to be utilized. The dominant resources can be employed efficiently to escalate new productivity and generate more new job opportunities. However, crowding-out effect also appears when an international company enters through "merger" or "acquisition"; as a result, a "reasonable" downsizing will occur, crowding-out employees and cutting down employment. Moreover, the international companies usually have stricter criteria concerning employees' working 
skills than the local firms do. Therefore, it is a common phenomenon that local employees are laid off as a result of not meeting the skill requirements of the foreign companies. In addition, the foreign companies are more capital-intensive, so the operation mode should crowd out some employment in labor-intensive local companies. Entering of FDI will fuel the competition of the local market and eliminate the lamed companies, thereby causing a considerable level of unemployment and reducing job opportunities.

\subsection{Effect on Employment Distribution. From an industrial} perspective, the effects of FDI on the employment distribution in the three sectors will vary because of the different influence extent of FDI on three economic sectors. Compared with other sectors, the impact from FDI on the primary sector is not significant. The primary sector is mainly agriculture/farming and is usually run by units as "family," so it does not require additional employees. Furthermore, the agricultural industry is vital to national well-being and the people's livelihood, so the authorities will usually impose more restrictions on foreign entities wishing to engage in this field. As a result, foreign companies will make relatively low investment in this sector. In addition, related technologies are currently advancing at blinding speed. Since the agricultural industry also applies modern methods to production, this will lead to less demand on the labor force. Consequently, the FDI certainly will not have any remarkable impact on the primary sector.

In China, the secondary sector, mainly manufacturing, always plays the leading role in the national economy, and FDI weighs heavily in this sector. Therefore, FDI has a more significant influence on employment in this sector. In the contemporary society, after material demands have been fulfilled, the demand for incorporeal service and spiritual satisfaction is boosting, which leads to the tertiary sector blossoming. Accordingly, foreign companies' direct investment into the tertiary sector will keep increasing. The service industry of labor demand is large so that FDI will surely have a greater scale of influence on employment in the tertiary sector.

2.3. Effects on Employment Quality. FDI has both positive and negative effects on employment quality. In the positive aspect, Cui and Li [4] suggest that FDI can contribute to the improvement of employment quality in the host countries. Foreign companies often offer better wages, benefit packages, and working environment; they also introduce new know-how and technologies to the employees in the host countries. Most of the foreign companies put a lot of effort into quality training and enhancing workers' skills so that, after being recruited, employees have the opportunity to get training to improve various abilities. Meanwhile, the employees' quality and skills will be cultured and improved due to a superior working environment.

The negative effects usually appear in regard to the foreign companies' negligence of employees in host countries. More and more foreign enterprises discriminate against the host country's social security system for the employees that mainly happens in small-sized foreign companies, which manifests as some or all employees are unable to obtain basic social security services. In order to reduce the cost, some foreign companies even provide very undesirable and poor working conditions with no security assurance, which raises considerable safety concerns about the working environment. In conclusion, the analysis on the quantity, distribution, and quality reveals that FDI has both positive and negative effects on local employment. The following sections present analysis on FDI's specific effects on the three aspects through empirical analysis.

\section{FDI in Shanghai}

The FDI started to flow into China in 1979 but did not reach the Yangtze River Delta region until 1986, despite a few years during which actual FDI inflow dropped, but the trend of foreign investment in actual use went up by year, and employment grew in Shanghai between 1986 and 2015 constantly. In fact, this study adopted the statistics data from 1981 to 2015.

Cao [5] had explored how Shanghai dealt with FDI along with the situation of employment, and the results indicated the FDI flows in Shanghai can be divided into four stages. The beginning stage was from 1986 to 1991. In this period, China's open policy focused on the southern regions like the Pearl River Delta region, which included Shenzhen, Zhuhai, Shantou, and Xiamen.

Chen and $\mathrm{Wu}[6]$ pointed out that China's FDI is mainly concentrated in coastal areas, attracting a large number of migrant workers from the mainland. This kind of population migration related to FDI may have an impact on China's inland urbanization. However, there is little research on this issue. This paper aims to study the regional impact of FDI on China's inland urbanization. The research had found that FDI has a negative interregional impact on inland urbanization in average. However, the impact of FDI from different trade patterns in coastal and inland areas on China's inland urbanization is different.

In this stage, a large number of foreign companies were set up in Pearl River Delta, but Shanghai just had scarce FDI in actual use; meanwhile, the employment experienced no apparent fluctuation. Basically, total employment was maintained at 8 million approximately.

Skyrocketing stage was from 1992 to 1997. During this period, FDI flows into Shanghai which actually reached a climax. The FDI in actual use in Shanghai was US $\$ 1.3$ billion in 1992, and the total FDI amount exceeded US $\$ 2.3$ billion in 1993; FDI has reached US\$3.2 billion in 1994, US $\$ 4.7$ billion in 1996, and US $\$ 4.8$ billion in 1997. Meanwhile, total employment remained at a relatively stable state. The total employment in Shanghai was 8.069 million people in 1992 and reached to 8.5 million in 1997.

In 1997, the financial crisis spread rapidly to most Asian countries so that FDI in actual use showed a negative growth in Shanghai. The growth rate was $-24.3 \%$ in 1998 and $-16.4 \%$ in 1999 . As a result, total employment also had negative growth rate in this phase, while the total 
employment reduced $1.3 \%$ in 1998 and lost $2.9 \%$ in 1999 statistically. Finally, experts called the following short and unusual period "Adjustment and Shrinking stage" between 1998 and 1999.

Next stage was from 2000 to 2008, called "Sustained Growth stage." During this period, FDI in actual use surged, US $\$ 3.16$ billion in 2000 , US $\$ 4.392$ billion in 2001, and over US $\$ 5$ billion in 2002, and had reached to US\$10 billion in 2008. At the same time, the number of total employment in Shanghai had reached to 10.53 million people.

3.1. FDI Inflow to Three Sectors in Shanghai. Based on results of former research studies, FDI has mainly pooled in the tertiary sector, followed by the secondary, and was least in the primary sector. For example, the actual FDI inflow to the tertiary sector in Shanghai was US $\$ 6.8$ billion in 2008, which was $67.8 \%$ of the total actual FDI inflow for the entire year. In the mean period, it was US\$3.2 billion for the secondary sector, which was $32.09 \%$ of the total, while the primary sector gained US\$13 million from FDI, which was a paltry $0.13 \%$ of the total. This ratio is still stable until the latest statistic in 2015 . It is pretty clear that the tertiary sector had attracted more foreign capital than the secondary and primary sector; in other words, the extent of FDI effects on the tertiary industry is several times larger than the secondary and primary sector.

In fact, the primary sector always remained at the lowest level. For example, FDI amount is US\$6 million in this sector in 2000, the secondary sector received US\$1.59 billion FDI in 1999, meanwhile, the tertiary sector took US $\$ 1.54$ billion. A greatest disparity happened in 2002 when the secondary sector gained US\$3.13 billion FDI, the tertiary sector merely acquired US\$1.88 billion, and the gap was US\$1.25 billion. Nevertheless, the FDI flows to the tertiary sector surpassed that to the secondary in 2003 and received the highest amount of FDI by comparing the other two sectors. The trend of FDI flows to the secondary sector kept descending since 2004; it was US\$3.587 billion in 2004, and the FDI amount was cut down to US\$2.597 billion in 2007. Meanwhile, the FDI amount was ascending in the tertiary sector, and the FDI amount had increased from US\$3.337 billion in 2003 to US\$6.835 billion in 2008 .

3.2. Employment Quantity. Based on the panel data of 262 cities in China with a range from 2004 to 2012, by using the GMM model of the dynamic panel system and regression technology of instrumental variables, this paper provides empirical research of the impact of FDI on China's urbanization [7]. This research has found that FDI has played a significant positive role in China's urbanization development. However, the positive role of FDI on urbanization development varies from region to region. Foreign direct investment has a positive effect on the urbanization of coastal areas but has little or no significant effect on the urbanization of inland areas. The analyzed results indicate that the factors such as economic structure, economic development level, fixed asset investment level, and urban population scale are important determinants of China's urbanization other than FDI solely.

China Second National Economic Census indicates that the number of employees hired by foreign companies was 1.1337 million people in Shanghai in 2008 , that is, $10.76 \%$ of the total employment, which means 10.5324 million people. In other words, out of every 100 employees, 10.5 worked for foreign companies. In 2016, employees hired by foreign companies numbered over 2 million and over $20 \%$ of the total employment.

China Second National Economic Census also indicates that, between 1999 and 2008 except for 2008, the number of foreign companies was increasing in Shanghai yearly, and the employment in 2007 was 1.2378 million. In percentage terms, the employment in foreign companies in Shanghai was 0.568 million people during 1999 , which was $6.24 \%$ of the total employment in $1999,8.08 \%$ in $2001,10.04 \%$ in $2003,10.41 \%$ in 2005 , and $13.62 \%$ in 2007 . Although the financial crisis in the second half of 2007 impacted employment in Shanghai, the employment in foreign companies shows an escalation trend yearly. Employees hired by the foreign companies were cut to 1.1138 million people in 2008 , and the percentage dropped to $10.58 \%$. However, employment in foreign enterprises increased in overall level, and the percentage compared with the total employment climbed steadily.

The analysis shows that the FDI in actual use in Shanghai kept growing every year and both total employment and employment in foreign companies were also increasing. With regard to the three sectors of the economy, FDI flooded into the tertiary sector, followed by the secondary, and the primary got the least. This research finds that FDI certainly affects the amount of employment and the employment distribution in the three sectors of the economy. The next section presents an empirical analysis on the effects to employment caused by FDI in Shanghai by establishing relevant regression models.

3.3. Employment Distribution. Employment showed an obvious disparity among the three sectors in Shanghai. Before the 21st century, employment was clustered in the secondary sector, but employment in the tertiary sector exceeded that of the secondary to become the major hiring industry since 2000 .

In regard to the total employment in the three sectors, employment in the primary sector was 2.24 million people in 1979 and then was reduced to 0.49 million in 2008. The proportion shrank from $31.55 \%$ to $4.69 \%$, a drop of 26.86 percentage points (pp) within 30 years. The trend implies that the structure of a society moves towards industrialization and urbanization when a massive amount of surplus agricultural labor transfers to the secondary and tertiary sectors.

The proportion of employment in the secondary sector was expanding in Shanghai between 1979 and 1990; in percentage form, it was $46.43 \%$ in 1979 and reached $59.30 \%$ in 1990. It showed a decreasing trend starting from 1991. The employment proportion in the secondary sector shrank 
from $59.04 \%$ in 1991 to $40.27 \%$ in 2008 . The manufacturing industry was no longer an "accumulator" to increase employment. However, employment in the tertiary sector kept expanding in Shanghai. The employment in the tertiary sector increased from $21.59 \%$ in 1978 to $72.64 \%$ in 2013. Moreover, the employment in the tertiary sector has exceeded than that in the secondary sector since 2000 .

3.4. Employment Quality. Based on the research of Chen and $\mathrm{Wu}$ [6], the FDI and exports had significant effects on China's urbanization. By analyzing the data of 262 prefecture level cities in China from 2004 to 2013, with the method of generalized moment model of the dynamic panel system of instrumental variable regression, the research finds that FDI and exports play positive roles in China's urbanization significantly. However, the impact of FDI and exports on urbanization varies from region to region. FDI has a positive and significant impact on the urbanization of coastal areas but has no impact on the urbanization of inland areas. Export has a positive and significant impact on the urbanization of coastal and inland areas, but the impact of coastal areas is much greater than that of inland areas. The results indicate that attracting more FDI and promoting exports will contribute to China's urbanization, especially in the inland areas.

The employment quality includes the working environment, wages, and benefits, as well as the ability improvements. Based on former research results, researchers recognized FDI inflow has had significant effects on the employment quality in Shanghai, but the effects, also, are both positive and negative.

In general, FDI accelerates the improvement of the minimum wages, employee benefits, and the development of individual's ability. Firstly, foreign companies always provide higher salary and better working environment than local employers. According to "Shanghai Statistical Yearbook," wages in foreign companies are often higher than the ones in the state-owned or the public sectors.

Table 1 reveals that the average wages in foreign companies were higher than those in the state-owned enterprises and the public sector between 1999 and 2006. The wages in the foreign companies compared with the state-owned and public sectors were 1.13 times and 2.67 times greater, respectively.

International corporations usually provide very competitive packages, which included pension, medical, work injury, unemployment, maternal insurances, and house funds, as well as a career development plan and more stable future clearly. At the same time, international corporations' policies focus on personal skills and improving quality of work so that the foreign companies usually provide newly hired employees with vocational training. For example, Unilever's subsidiary in Shanghai lays stress on strengthening employees' international competitiveness particularly. Unilever in Shanghai has a comprehensive system for aiding employees' improvement and individual's future development. There is a division which seeks in-house talents and future leaders in Unilever and assists the employees to obtain global perspectives through working, training courses, and international relocation. In Unilever, all employees are open minded and ready for challenging tasks and improvement of themselves.

In addition, foreign companies usually find relevant $\mathrm{R} \& \mathrm{D}$ departments locally when entering a foreign market. The introduction of $\mathrm{R} \& \mathrm{D}$ departments always helps to enhance employees' personal abilities. According to the statistics, there are 257 foreign companies of "Fortune" top 500 enterprises settled in Shanghai with 1,884 investment projects and $45 \mathrm{R} \& \mathrm{D}$ centers until 2006. The R\&D and technical centers of foreign companies enable local engineers to obtain the latest know-how, which will improve human resources in Shanghai and build up their own talent pools. Additionally, FDI also has indirect effects on improving the quality of employment in Shanghai. Competition between foreign and local companies stimulates the local companies to improve their management and methods of production. As a result, the productivity of the local companies will increase, and job training will be strengthened, which will indirectly improve the employment quality in Shanghai.

On the contrary, FDI also has a negative effect on the employment quality in Shanghai, such as stability. For example, numerous foreign companies were shut down due to the financial crisis in 2007, and countless employees were laid off. According to the Shanghai Statistic Bureau, the employees hired by foreign companies numbered 1.2378 million in 2007, and the number was cut to 1.1138 million in 2008 , which indicates the foreign companies cut redundant workers for cost-down reasons when encountering crises. However, other figures show that the total employment in Shanghai was 9.0908 million people in 2007 and 10.53 million in 2008, which signified growth of 1.44 million in total labor so that total employment in Shanghai was increasing instead of falling during the financial crisis. In fact, the employment growth occurred in the local companies' recruitment plan. From this perspective, employment in local companies is more stable than in foreign subsidiaries. The trend of employment in foreign companies is to have shorter term contracts when an enterprise faces falling profit. It will lay off workers without any hesitation, and as the workers have insufficient job security, this leads to employment instability.

\section{Model and Results}

4.1. Model and Variables. Most of the relevant studies suggest that the introduction of FDI will have a direct effect on the employment in the foreign companies so that this research chose the "actual FDI inflow in Shanghai" as the independent variable, while chose the "amount of employment in foreign companies" as the dependent variable to establish the following model:

$$
\begin{aligned}
& \ln Q_{t}=\beta_{0}+\beta_{1} \ln \mathrm{FDI}_{t-1}+\varepsilon_{t}, \quad(\text { Model A) } \\
& \ln Q_{t}=\beta_{0}+\beta_{1} \ln \mathrm{FDI}_{t-1}+\beta_{2} \ln \frac{W}{P_{t-1}}+\varepsilon_{t} .
\end{aligned}
$$


TABLE 1: Relevant information on the average wages in different kinds of enterprises.

\begin{tabular}{lcccccccc}
\hline & 1999 & 2000 & 2001 & 2002 & 2003 & 2004 & 2005 & 2006 \\
\hline Foreign companies & 19,728 & 21,158 & 25,572 & 26,365 & 29,106 & 29,282 & 35,709 & 40,683 \\
State-own enterprises & 16,852 & 18,865 & 21,961 & 24,719 & 28,406 & 31,287 & 36,077 & 36,010 \\
Public sector & 11,127 & 12,020 & 13,693 & 14,851 & 16,973 & 19,986 & 22,486 & 15,209 \\
\hline
\end{tabular}

Source: Shanghai Statistical Yearbook 2000-2007 and China Financial Statistical Yearbook.

TABle 2: Descriptive statistics variables.

\begin{tabular}{|c|c|c|c|c|c|c|c|}
\hline & $N$ & Minimum & Maximum & Mean & Std. deviation & Skewness & Kurtosis \\
\hline $\operatorname{lnFDI}$ & 35 & 5.70 & 14.43 & 11.8465 & 2.47904 & -1.181 & 0.452 \\
\hline $\ln W P$ & 35 & 2.14 & 6.97 & 4.6308 & 1.63621 & -0.148 & -1.451 \\
\hline $\ln Q$ & 35 & 4.55 & 4.60 & 4.5774 & 0.01605 & 0.327 & -1.368 \\
\hline
\end{tabular}

TABLe 3: Results of Model A and Model B.

\begin{tabular}{lcc}
\hline Variables/estimation & Model A & Model B \\
\hline $\ln \mathrm{FDI}_{t-1}$ & $0.006^{*}(0.001)$ & $0.007^{*}(0.001)$ \\
$\ln W / P_{t-1}$ & - & $0.001^{*}(0.002)$ \\
$C$ & $4.644^{*}(0.007)$ & $4.627^{*}(0.006)$ \\
Adjusted $R^{2}$ & 0.756 & 0.850 \\
$F$ statistics & $106.168^{* * *}$ & $97.082^{*}$ \\
Observation & 35 & 35 \\
\hline
\end{tabular}

Note: the numbers in parentheses are standard errors. ${ }^{*}$ The estimated coefficients are statistically significant at $1 \%$.

In Model A, " $Q$ " stands for the "amount of employment in foreign companies in Shanghai," and "FDI" stands for the "actual FDI inflow in Shanghai." " $\varepsilon_{t}$ " stands for random error, which reflects the uncertainties between "Q" (refers to the amount of employment in foreign companies) and "FDI" (refers to the actual FDI inflow).

In Model B, " $Q$ " stands for the "amount of employment in foreign companies in Shanghai," and "FDI" stands for the "actual FDI inflow in Shanghai" that are the same as Model A. Besides, " $W$ " stands for nominal wage (refers to the rate of pay employees are compensated) and " $P$ " stands for Consumer Price Index, where " $W / P$ " is defined as the real wage (which is the nominal wage adjusted for inflation) in the proposed Model B and " $\varepsilon_{t}$ " stands for random error that reflects the uncertainties between "Q" and "FDI."

Table 2 shows descriptive statistics of explanatory variables. The above analysis shows that the coefficient of determination $R^{2}$ is 0.756 in Model A and 0.850 in Model B, which indicate both equations of Model A and Model B are fitting good. The degree of freedom is 35 , and the critical number coefficient is greater than $F$ value $=0.05$, which displays a significant linear relationship and shows the explanatory variable and response variable are at high levels in regard to the interpretation. According to the insight of $t$ value, the critical number is $t$ which shows the FDI has a significant effect on the gross employment in Shanghai, under the condition that the significance level was present at $5 \%$.

4.2. Empirical Results. In the empirical stage, researchers adopted the data from 1981 to 2015 in China National
Bureau of Statistics as the sample to deal with the question of "When the discrepancy of the relative figures is huge, will it seriously impact the regression results?" Therefore, the currency of FDI value was converted from US $\$ 100$ million to $\mathrm{RMB} ¥ 100$ million for the regression analysis. " $Q$ " refers to the "amount of employment in foreign companies in Shanghai," while takes "per 10 thousand people" as the unit. The results from GLS regression analysis are listed in Table 3.

The coefficients of determinations of both equations show goodness of fit. Therefore, Model A indicates that $\operatorname{lnFDI}$ has an obvious negative effect with total employment. In fact, though FDI has created a large number of new jobs, it still squeezed numerous existing jobs. As a result, new jobs are less than squeezed, which answered why the empirical result is negative.

In Model $\mathrm{B}$, the authors add variable $\ln W / P$ in the calculation process, and after $\ln W / P$ has been put in, the prior variables $\ln F D I$ had no significant relationship with total employment since $\ln F D I$ and $\ln W / P$ are highly correlated. The newly added variable $W / P$ has made the equation repetition explanation. At the same time, $\ln F D I$ in Model B is not as important as it was in Model A. As a result, FDI created many high-end jobs, and these jobs have promoted the whole employment quality; however, highend positions openings have replaced a large number of existing low-end positions.

\section{Conclusion and Suggestion}

Based on empirical analysis on the effects of FDI in Shanghai, the conclusions and suggestion regarding the quantity, distribution, and quality of employment are as follows.

The regression analysis on the relationship between FDI and the quantity of employment in Shanghai indicates that FDI will reduce the total employment. Even though a large number of employees are hired by foreign companies, it created still small than squeezed. Because efficient positions will take over inefficient jobs previously, that is why, FDI has a negative relationship with employment quantity. On the contrary, FDI has an obvious promotion about employment quality because high-end jobs have also squeezed the existing low-end jobs, thus promotion for the whole employment quality. 
From previous analysis, if Shanghai has a high unemployment rate in the future, more FDI flow will make this situation more seriously; on the contrary, if Shanghai with an obvious labor shortage in the future, more FDI flow will ease this problem, which also further promote the employment quality.

Researchers also suggest that Shanghai should attract more FDI inflow by utilizing its exceptional location, abundant labor force, and enormous economic capabilities in order to enable foreign companies to expand and create more high-end job opportunities. In this stage, the types of FDI in Shanghai are mainly joint venture, wholly-owned, and associated enterprise. Therefore, Shanghai can innovate its own way of exploiting the FDI and develop more channels for increasing the inflow. Shanghai's government could encourage the local private companies to have more interactions with foreign companies and use these platforms for local companies to learn from foreign companies. Meanwhile, the local private sector can also learn the methods of internationalizing, such as fund raising in the international financial market, joint venture, or incorporation with foreign companies. Furthermore, Shanghai should improve its mechanisms of labor market operation to encourage the flow of various professionals among different organizations, taking full advantage of the FDI. Eventually, Shanghai should keep the economy growing at stable rates, while creating more high-end job opportunities.

\section{Data Availability}

The FDI data used to support the findings of this study are available from the corresponding author upon request.

\section{Conflicts of Interest}

The authors declare that they have no conflicts of interest.

\section{References}

[1] F. Paukert, "Income distribution at different levels of development: a survey of evidence," International Labour Review, vol. 108, no. 97, 1973.

[2] P. S. Ko, C. C. Wu, Y. S. Mai, and Z. R. Xu, "A study of three sectors employment effects resulting from foreign direct investment-empirical analysis on the data from Shanghai," International Journal of Business Administration and Management Research, vol. 4, no. 2, pp. 19-24, 2018.

[3] Y. Tang, "How FDI affects the employment in China," Market Weekly, Theory Study, 2008.

[4] X. Cui and Z. Li, Empirical Analysis on the Economic Effects by FDI in China, World Economic Forum, Geneva, Switzerland, 2003.

[5] H. Cao, Analysis on FDI in China by Stage, The Modernization of Emporia, Emporia, KS, USA, 2009.

[6] C. Chen and Y. Wu, "Interregional impact of foreign direct investment on China's inland urbanization," The Singapore Economic Review, vol. 64, no. 4, pp. 997-1017, 2019.

[7] Y. Wu and C. Chen, "The impact of foreign direct investment on urbanization in China," Journal of the Asia Pacific Economy, vol. 21, no. 3, pp. 339-356, 2016. 